\title{
Effect of the arrangement of reinforcement on the behaviour of reinforced concrete slabs*
}

\author{
by R. Taylor, BSc, DIC, AMICE, D. R. H. Maher, MSc and B. Hayes, BSc
}

\section{Contribution by R. D. Anchor \\ G.K.N. Reinforcements Limited}

The writer would like to comment on the relevance of certain details of the authors' tests to everyday design.

In the first place, the materials used are not typical of present practice. A design concrete cube strength of $5,000 \mathrm{lb} / \mathrm{in}^{2}$ is never used for slabs, the compressive stresses rarely being significant. A strength of 3,000 $\mathrm{lb} / \mathrm{in}^{2}$ would be more realistic. The reinforcement which is described as 'annealed mild steel bar' has properties which are appreciably in excess of the requirements of the forthcoming British Standard for mild steel. It would be interesting to know the shape of the stress-strain curve. Plain mild steel, although popular with investigators, is not used very extensively in building structures. The reinforcement that is almost universally used with industrialized construction is welded fabric made of hard-drawn wire or bars. It would be interesting to continue the tests that have already been made by experimenting with the use of these types of steel.

The authors state that "designers have apparently lost sight of" the possibility of economizing in reinforcement by using a variable bar spacing. This is not the case. Designers are conscious that detailing and fixing bars with variable spacings is an expensive nuisance liable to lead to errors in the office and on site. Indeed, in some offices it is not even the practice to stop-off bars in slabs.

The cost of bar reinforcement, fixed in position in a slab, is typically about one-third to one-quarter of the total cost of the slab, and the greatest economy to be achieved with the authors' designs is to convert from mild steel to high-yield steel, showing a saving of about $15 \%$ in the cost of reinforcement.

It is noted in the paper that the thickness of the slab was checked. Did the authors also check the actual cover to the reinforcement when the tests had been completed? Accuracy in this imension is obviously important.

*Pages 85 to 94 of Magazine No. 55
The problems of cracking and deflexions are discussed in relation to the CEB recommendations and the writer has always assumed that the crack widths stated in that document are for instantaneous loading. The writer would agree with the authors that, when the effects of long-term loading are taken into account and particularly in the case of ribbed floors over about $25 \mathrm{ft}$ span (which are designed as slabs), it is not possible to satisfy the B.S. 449 requirements of a deflexion/span ratio of $1 / 360$. Indeed, the span/depth ratios in CP 114 (1965) are quite inadequate for this type of construction, probably largely because the cracking load is relatively small. In spans of $25 \mathrm{ft}$ or more, it is often necessary, in the writer's opinion, to limit the total actual deflexion rather than to specify arbitrary span/depth or span/deflexion values.

\section{Reply by the authors}

First we must reject the idea implied by $\mathrm{Mr}$ Anchor that research should follow everyday practice. But neither do we agree that the materials used are so untypical. Surely the concrete cube strength of 3,000 $\mathrm{lb} /$ in $^{2}$ quoted by $\mathrm{Mr}$ Anchor is the specified minimum value, and 'typical' actual strengths are well in excess of this? Mr Anchor states that compressive stresses are rarely significant; we would add a corollary: the behaviour of slabs is not significantly altered by changes in concrete strength.

The reinforcement had a constant yield stress up to a strain of $2 \%$. This is not untypical for mild steel of diameter greater than $\frac{1}{4}$ in. It should be appreciated that mild-steel bars of diameter less than $\frac{1}{4}$ in. do not exhibit this constant yield stress because of strainhardening during cooling in manufacture. Thus, in order to simulate 'typical' mild steel, it is essential to anneal the small diameters. Failure to do so could invalidate any attempt to apply the results to actual design. That the yield stress of the steel exceeds that of typical mild steel is surely irrelevant. After all, the bars can be regarded as equivalent to ordinary mild steel of slightly larger diameter. 
Clearly, high-strength bars should be used where this is shown to be economical. However, the authors would be surprised if the saving indicated by $\mathrm{Mr}$ Anchor is generally applicable. Indeed, for many slabs designed to CP 114, the minimum percentage requirements would preclude the use of such reinforcement

Nevertheless it would be interesting to continue the tests with high-strength steels. (If money were forthcoming from industry, they could be continued.) Their short yield and strain-hardening properties present some interesting problems. Certainly any application of the results of the current tests to such bars is conservative.

Hillerborg's method of design leads directly to variable reinforcement. The designer must decide whether the detailing and the extra supervision on site are justified. It was not intended that designers should adopt large numbers of strips. Indeed an aim of the tests was to justify the use of wide strips with a simple reinforcement layout.

The cover to the reinforcement was accurately maintained by the use of $\frac{3}{16}$ in. diameter supporting bars. This was easily verified after the test at the position of the yield lines.

The authors agree with Mr Anchor's remarks on deflexions. The code limitations on span/depth ratios are hardly justified. Clearly, the thickness of the slab should be related to the intensity of loading. Moreover, more thought must be given to what constitutes the limit of acceptable deflexion. 